\title{
Pozzolanic activity of a spent fluid catalytic cracking catalyst residue
}

\section{Pedro Garcés}

Departamento Ingeniería de la Construcción, O. Públicas e Infraestructura Urbana, Universidad de Alicante, Spain

Fred P. Glasser

Department of Chemistry, University of Aberdeen, UK

Daniel R. M. Brew*

Department of Chemistry, University of Aberdeen, UK

\section{Emilio Zornoza}

Departamento de Ingeniería de la Construcción, Obras Públicas e Infraestructura Urbana, Universidad de Alicante, Spain Jordi Payá

Instituto de Ciencia y Tecnología del Hormigón. Univ. Politécnica de Valencia, Spain

The reaction between a spent fluid cracking catalyst (FC3R) residue and portlandite was monitored over 56 days using several material characterisation techniques. The results showed that the residue was heterogeneous and composed of reactive and non-reactive fractions and that both fractions contained silicon and aluminium. After 56 days, the development of $\mathrm{C}-\mathrm{S}-\mathrm{H}$ gel was evident; part of the catalyst residue was pozzolanic. The $\mathrm{CH}$ combination could be monitored by thermogravimetry or X-ray diffraction, by measuring the signal corresponding to $\mathrm{CH}$. However, due to the low crystallinity of cementing products and their complex stoichiometry, the above-mentioned techniques were less able to characterise C-A-S-H. However, nuclear magnetic resonance techniques allowed the evolution of the pozzolanic reaction to be evaluated and the hydrate products to be characterised.

\section{Introduction}

Spent fluid catalytic cracking catalyst (FC3R), recovered from petrol refineries, shows significant pozzolanic activity in Portland cement and lime pastes (Hsu et al., 2001; Pacewska et al., 2002; Payá et al., 1999, 2001, 2002, 2003a; Su et al., 2000, 2001; Wu et al., 2003). Although the source of FC3R may be different depending on the refinery, a previous study performed on five wasted catalysts coming from five different origins has shown that the source and the differing processing of the catalysts do not produce different behaviour, as the five studied materials presented a similar pozzolanic reactivity (Payá et al., 2009). One of the difficulties of introducing a novel pozzolanic material into use is to ensure that the material has completely reacted with the cement or hydrated lime or, if the reaction is incomplete, it retains potential for further reaction. Due to the poor crystallinity of spent catalyst residues and the inherent challenges associated with their structural quantification, very little has been published on its reaction. Compressive strength development can, of course, indicate reaction as a function of time but the relationship between strength gain and reacted fraction does not provide an accurate description of the pozzolanic activity of the spent catalyst.

In the present study, a spent catalyst residue, designated FC3R, has been reacted with calcium hydroxide so that the pozzolanic

* Current address: Institute of Materials Engineering, Australian Nuclear Science \& Technology Organisation, Menai, New South Wales, Australia reaction can be monitored free of interference from supplementary cementitious materials and products, especially those containing iron. The pozzolanic activity and course of reaction have been investigated using the following microstructural characterisation techniques: powder X-ray diffraction (XRD), Fourier transform infra-red spectroscopy (FT-IR) and ${ }^{27} \mathrm{Al}$ and ${ }^{29} \mathrm{Si}$ solidstate magic angle nuclear magnetic resonance spectroscopy (MAS NMR).

The special features of this study on FC3R relate both to the novel nature of the residue and to the use of calcium hydroxide as the activator, avoiding the presence of cementing materials from the cement hydration. In this manner the evolution of the simple pozzolanic acid-base reaction (acid= pozzolan; base = $\mathrm{CH})$ can be monitored without interference.

\section{Experimental}

The petrol refinery which supplied the spent FC3R residue was BP Oil España (Castellón, Spain). The reactivity of the catalyst was increased to the optimum particle size distribution with the aid of a laboratory ball mill (Gabbrielli Mill-2) (Payá et al., 1999, 2001). In the preparation of the lime pastes, general purpose laboratory-grade (96\% purity) calcium hydroxide (Panreac S.A., Spain) was used. The major oxide composition of spent FC3R, as supplied by the manufacturer, is given in Table 1. Table 2 shows the paste formulations that were prepared with the reagent proportions and the analyses that were performed for characterisation. The pastes were prepared to a uniform 


\begin{tabular}{lclr}
\hline Oxide & FC3R & Oxide & FC3R \\
\hline $\mathrm{SiO}_{2}$ & 48.2 & $\mathrm{~K}_{2} \mathrm{O}$ & $<0.01$ \\
$\mathrm{CaO}$ & $<0.01$ & $\mathrm{SO}_{3}$ & 0.04 \\
$\mathrm{Al}_{2} \mathrm{O}_{3}$ & 46.0 & $\mathrm{TiO}_{2}$ & 1.65 \\
$\mathrm{Fe}_{2} \mathrm{O}_{3}$ & 0.95 & $\mathrm{Cl}$ & $<0.01$ \\
$\mathrm{MgO} \mathrm{Ol}$ & $\mathrm{LOI}$ & 1.50 \\
$\mathrm{Na}_{2} \mathrm{O}$ & $<0.01$ & IR & 11.11
\end{tabular}

nuclei which are fixed in rigid structures such as ${ }^{29} \mathrm{Si}$ in cements or silicate minerals. The technique can determine which nuclei are in close vicinity to hydrogens - in the present study hydrogens would be present as hydroxyl groups. The ${ }^{29} \mathrm{Si}$ and ${ }^{27} \mathrm{Al}$ nuclei under observation were referenced to the standards: tetramethyl silane and $1 \mathrm{~mol} / 1 \mathrm{AlCl}_{3}$, respectively.

\section{Results}

Table 1. Major oxide composition (in wt. \%) of spent FC3R

water : cement weight ratio $=0 \cdot 8$ and cured at room temperature $\left(22 \pm 5^{\circ} \mathrm{C}\right)$ in sealed containers at $\sim 100 \%$ relative humidity for the stated period of time. Prior to analysis, reaction was stopped by powdering the sample and quenching hydration by washing with acetone several times. The solid was filtered and dried at $60^{\circ} \mathrm{C}$ for $30 \mathrm{~min}$ in air.

A previous study (Payá et al., 2001) reported that spent residues from this refinery were composed of a faujasite-like material. From XRD, the crystallinity of the spent catalyst had degraded relative to fresh material. Therefore, to help in interpreting the instrumental data on systems containing the FC3R residue, synthetic commercial faujasite, referred to as 'faujasite' in this study, was also used to benchmark FT-IR and MAS NMR studies. The FT-IR measurements were carried out using a Fourier transform infra-red spectrophotometer (Perkin Elmer; model 1740). The spectra were collected in the wavenumber range from 400 to $4000 \mathrm{~cm}^{-1}$ and in an air atmosphere using the $\mathrm{KBr}$ pellet technique. Pellets were prepared by pressing a mixture of the sample and dried $\mathrm{KBr}$ (sample/ $\mathrm{KBr}$ approximately $1: 150$ ) at 5 tonnes $/ \mathrm{cm}^{2}$. Powder XRD patterns were collected using a Bruker D8 Advance diffractometer with twin Gobel mirrors using $\mathrm{CuK}_{\alpha}$ radiation. Data were collected over the the range $5<2 \theta<60^{\circ}$ with a step size of $0.02^{\circ}$. The NMR spectra were performed by a Varian UNITY Inova $7.5 \mathrm{~mm}$ MAS probe spectrometer with a $7.05 \mathrm{~T}$ ('300 MHz') Oxford Instruments magnet. Samples were spun in zirconia rotors at a maximum of $7 \mathrm{kHz}$. Sufficient scans of nuclei were collected to minimise signal degradation. Where appropriate, samples were crosspolarised using a contact time of $10 \mathrm{~ms}$. Cross-polarisation can be used when investigating very dilute nuclei and/or less mobile

Figure 1 illustrates the XRD pattern of spent FC3R catalyst residue. The residue contains both semi-crystalline and crystalline material. The broad hump feature at $2 \theta$ values between 20 and $30^{\circ}$ indicates the presence of semi-crystalline or amorphous material, as does the low signal: noise ratio of the pattern. Reflections pertaining to the mineral faujasite, $\mathrm{Na}_{2} \mathrm{O} \cdot \mathrm{Al}_{2} \mathrm{O}_{3} \cdot 4 \cdot 7 \mathrm{SiO}_{2} \cdot \mathrm{xH}_{2} \mathrm{O}$ (JCPDS file 39-1380) were identified. Minor reflections can be attributed to cristobalite (JCPDS file 76-0939), mullite (JCPDS file 73-1253) and quartz (JCPDS file 46-1045). These phases have been reported previously in XRD analyses of other spent commercial faujasite-based catalysts (Chen et al., 2004, Payá et al., 2001).

Figure 2 illustrates the XRD pattern obtained for sample FC3R0 ( $t=0$ days: within about $15 \mathrm{~min}$ after mixing). All major reflections correspond to portlandite $\left(\mathrm{Ca}(\mathrm{OH})_{2}\right.$; JCPDS file

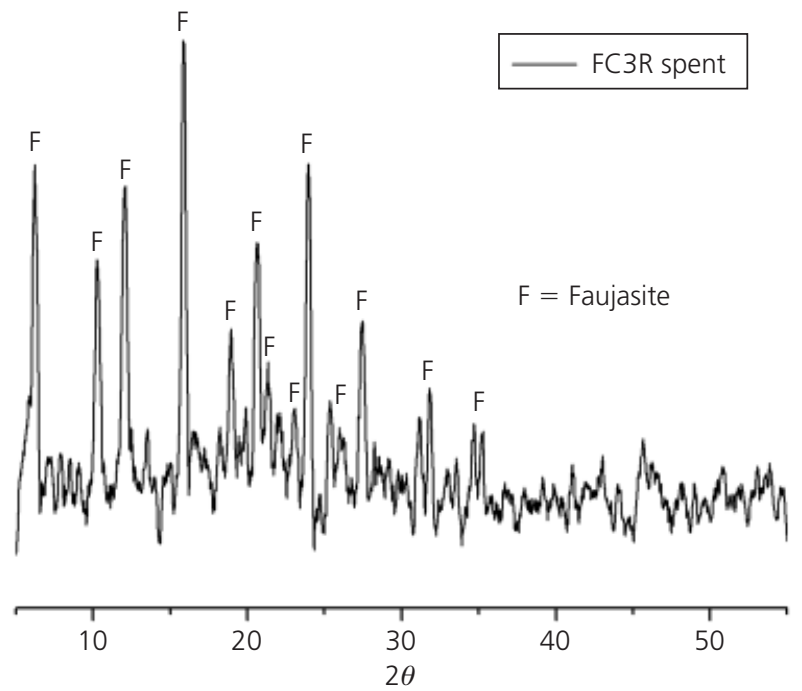

Figure 1. Powder XRD pattern for spent FC3R residue

\begin{tabular}{llcccc}
\hline Sample & Description (ratio) & Cure: days & XRD & FT-IR & NMR \\
\hline FC3R0 & FC3R/CH (3/7) & 0 & $\checkmark$ & & $\checkmark$ \\
FC3R1 & FC3R/CH (3/7) & 1 & & $\checkmark$ & \\
FC3R3 & FC3R/CH (3/7) & 3 & $\checkmark$ & & $\checkmark$ \\
FC3R7 & FC3R/CH (3/7) & 7 & & $\checkmark$ & \\
FC3R28 & FC3R/CH (3/7) & 28 & $\checkmark$ & $\checkmark$ & $\checkmark$ \\
FC3R56 & FC3R/CH $(3 / 7)$ & 56 & & & $\checkmark$
\end{tabular}

Table 2. Formulations of pastes and instrumental analyses made 
Advances in Cement Research

Volume 23 Issue 3
Pozzolanic activity of a spent fluid

catalytic cracking catalyst residue

Garcés, Glasser, Brew, Zornoza and Payá

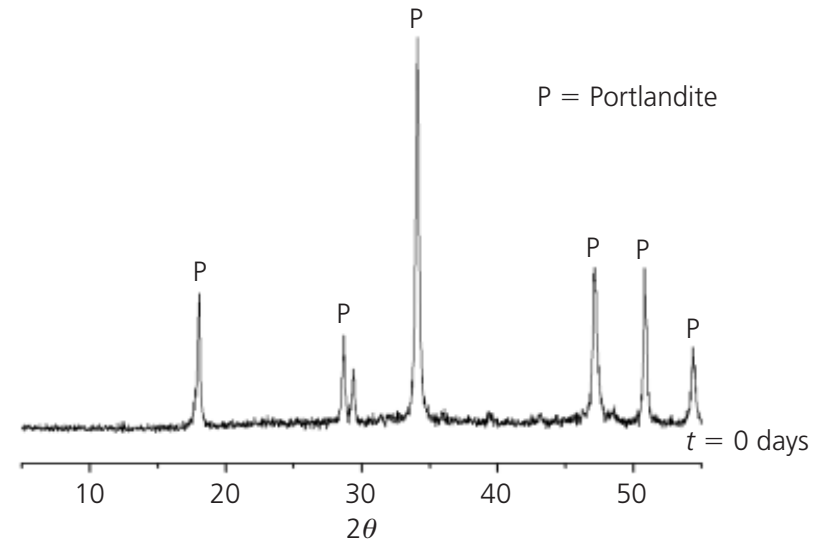

Figure 2. XRD pattern for FC3RO paste

04-793). Comparison of the XRD patterns obtained in Figures 1 and 2 shows that, in the latter case, peaks attributed to faujasite have apparently disappeared due to the highly crystalline nature of portlandite and the relatively low faujasite content. Figure 3 collates the XRD patterns of FC3R0, FC3R3 and FC3R28. In each case the major reflections also correspond to portlandite. The continued presence of $\mathrm{Ca}(\mathrm{OH})_{2}$ as a function of time can be clearly observed although it is evident that the intensity of the characteristic reflections diminish as the reaction time increases. At the same time, new reflections appear. The reflection situated near $2 \theta$ value of $12^{\circ}$ indicates the possible development of stratlingite, $\mathrm{Ca}_{2} \mathrm{Al}_{2}\left(\mathrm{SiO}_{2}\right)(\mathrm{OH})_{10} \cdot 2 \cdot 5 \mathrm{H}_{2} \mathrm{O}$ (JCPDS file 29-0285). This reflection strengthens as curing time increases.

Figure 4 presents the FT-IR spectra of faujasite, spent FC3R residue and fresh FC3R catalyst. In general the spectra for all three materials show some similarities. However, there are two main differences between spent and fresh FC3R. First, fresh FC3R gives rise to H-bonding absorptions located approximately

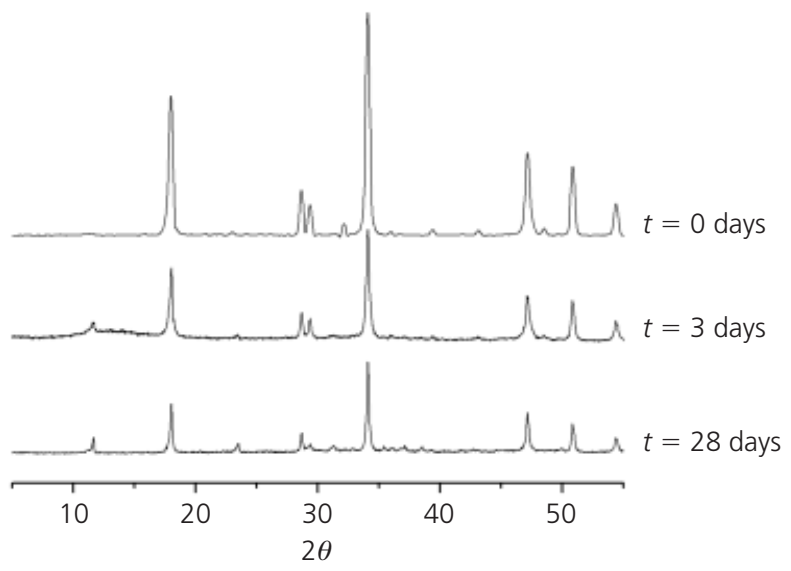

Figure 3. XRD patterns for FC 3RO, 3 and 28 as a function of curing time

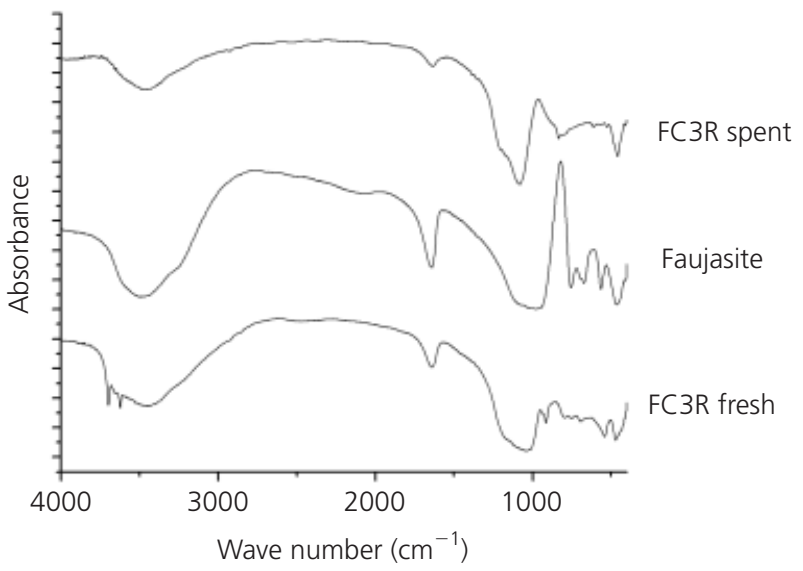

Figure 4. FT-IR spectra of spent and fresh FC3R and synthetic faujasite

at $3750 \mathrm{~cm}^{-1}$ indicative of molecular water. The conversion process, from fresh catalyst to spent FC3R residue, occurs under the influence of heat as well as chemical impurities and, as a result, these vibrations are absent. Second the silicate and aluminosilicate framework vibrations present in the spent residue, from about $1100-470 \mathrm{~cm}^{-1}$ and below, appear less well developed and have shifted slightly suggesting that the spent catalyst has a different network structure than fresh material. The spent residue also gives rise to a $\mathrm{OH}$ stretching and a deformation vibration at $3000-3500$ and $1640 \mathrm{~cm}^{-1}$, respectively. Table 3 collates the principal wavenumbers and their assignments which agree well with studies previously reported (Pacewska et al., 2000, Payá et al., 2003b).

Figure 5 presents the FT-IR spectra for mixtures of $\mathrm{Ca}(\mathrm{OH})_{2}$, FC3R1, FC3R7 and FC3R28. It can be seen that vibrations for $\mathrm{Ca}(\mathrm{OH})_{2}$ are present in all three FC3R spectra. There is little spectral difference between FC3R1 and FC3R7 (1 and 7 days hydration time) but after 28 days, significant pozzolanic reaction has occurred, as indicated by both the reduction in intensity of the sharp vibration at $3640 \mathrm{~cm}^{-1}$, assigned to hydroxide stretching from $\mathrm{Ca}(\mathrm{OH})_{2}$, and the broader hydroxide deformation absorption near $1500 \mathrm{~cm}^{-1}$.

\begin{tabular}{ll}
\hline Vibration $\left(\mathrm{cm}^{-1}\right)$ & Assignment \\
\hline $3000-3500$ & OH stretching $\mathrm{H}_{2} \mathrm{O}$ \\
1640 & OH deformation \\
1150 & Si-O stretching \\
1070 & Si-O(Al) stretching \\
800 & Si-O tetrahedra stretching \\
550 & Si-OH stretching \\
470 & Si-O-Si deformation
\end{tabular}

Table 3. FT-IR data for spent FC3R residue 


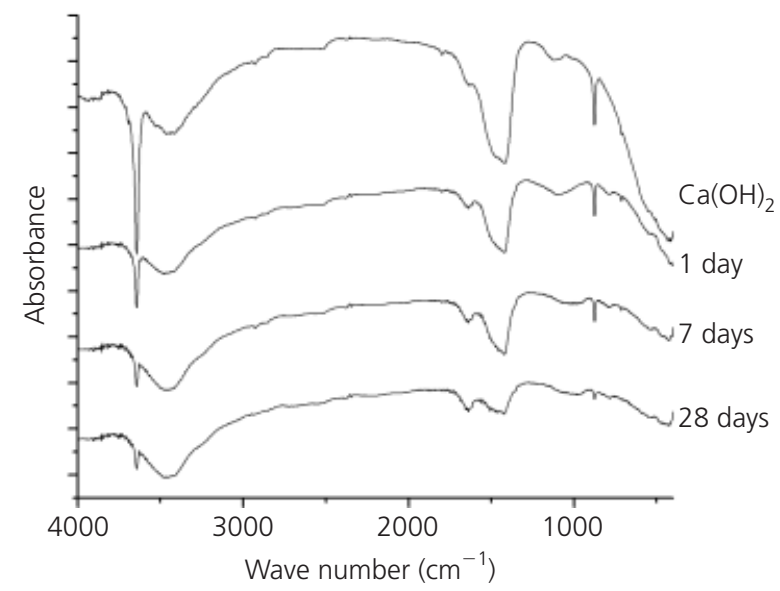

Figure 5. FT-IR spectra of $\mathrm{Ca}(\mathrm{OH})_{2}, \mathrm{FC} 3 \mathrm{R} 1, \mathrm{FC} 3 \mathrm{R} 7$ and FC3R28

The ${ }^{29} \mathrm{Si},\left\{{ }^{1} \mathrm{H}_{-}{ }^{29} \mathrm{Si}\right\} \mathrm{CP}$ and ${ }^{27} \mathrm{Al}$ MAS NMR spectra of spent FC3R residue are displayed in Figure 6. The spectra confirm that the spent residue was a heterogeneous mixture containing both crystalline and semi-crystalline phases. The sharp peak observed at $-108.4 \mathrm{ppm}$ suggests an ordered $\mathrm{Q}^{4}$ silicate phase, probably quartz and/or cristobalite, known from XRD to be present. A range of $\mathrm{Q}^{2}, \mathrm{Q}^{3}$ and $\mathrm{Q}^{4} \mathrm{Si}-\mathrm{O}(\mathrm{Al})$ environments are scattered between -115 to $-80 \mathrm{ppm}$. The ${ }^{27} \mathrm{Al}$ MAS NMR spectrum shows both broad and sharp peaks can be observed, indicative of a spread of $\mathrm{Al}-\mathrm{O}$ environments. The sharpest peak observed at $5.5 \mathrm{ppm}$ is partly obscured by broader peaks but arises from the presence of octahedrally-coordinated aluminium. The broader

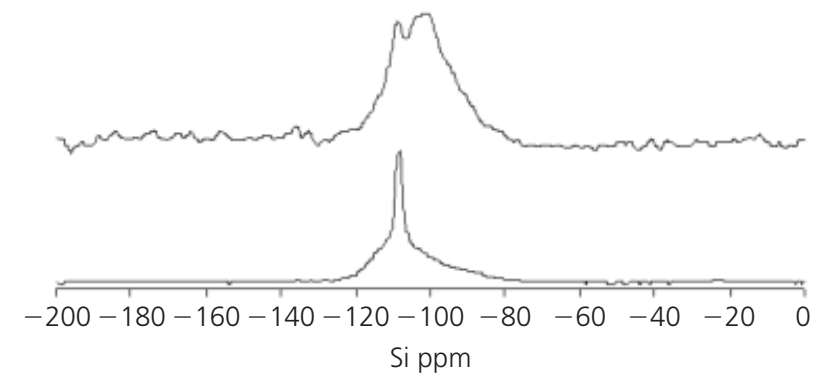

(a)

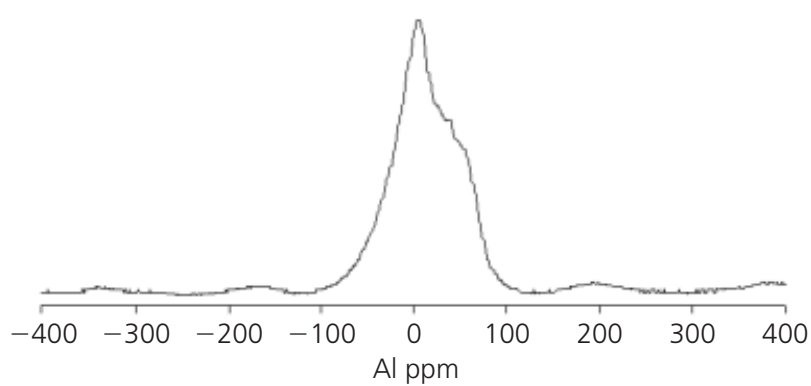

(b)

Figure 6. ${ }^{29} \mathrm{Si}\left((\mathrm{a})\right.$, lower) and $\left\{{ }^{1} \mathrm{H}-{ }^{29} \mathrm{Si}\right\} \mathrm{CP}\left((\mathrm{a})\right.$, upper) and ${ }^{27} \mathrm{Al}$ MAS NMR (b) spectra of spent FC3R residue peaks, located near 35 and $55 \mathrm{ppm}$, are characteristic of pentahedral and tetrahedral aluminium, respectively. The other feature of this spectrum, bands at $-400,-200,200$ and $400 \mathrm{ppm}$, are attributed to spinnining sidebands. These are artefacts due to the presence of trace quadrupolar nuclei, such as iron, sodium, etc. and, while they should be discounted as signal due to Al, they serve to further highlight the heterogeneity of the residue. Figure 7 presents the ${ }^{29} \mathrm{Si},\left\{{ }^{1} \mathrm{H}^{-29} \mathrm{Si}\right\} \mathrm{CP}$ and ${ }^{27} \mathrm{Al}$ MAS NMR spectra of faujasite. Five different $\mathrm{Si}-\mathrm{O}$ environments are associated with the material at $-84 \cdot 6,-89 \cdot 0,-93 \cdot 7,-98 \cdot 3$ and $-102 \cdot 2 \mathrm{ppm}$ and all have hydroxyls in close vicinity, indicating a homogeneous material. The most abundant shift at $-84.6 \mathrm{ppm}$ corresponds to a single type of $\mathrm{Q}^{2} \mathrm{Si}$ (chain silicates). The shift at $-89 \cdot 0$, while also in the $\mathrm{Q}^{2}$ range, is more likely to be a $\mathrm{Q}^{3}(2 \mathrm{Al})$ or $\mathrm{Q}^{3}(3 \mathrm{Al})$ environment: chain-branching $\mathrm{Si}-\mathrm{O}$ with two or three aluminium atoms close by; the aluminium nuclei interfere with the silicon nuclei response to the applied magnetic field resulting in a lower chemical shift than expected. The resonances at $-93 \cdot 7,-98 \cdot 3$ and $-102.2 \mathrm{ppm}$ are $\mathrm{Q}^{3}$ chain-branching $\mathrm{Si}-\mathrm{O}$ without aluminium nuclei as next-to-nearest neighbours. In addition, Figure 7 shows a sharp ${ }^{27} \mathrm{Al}$ shift at $-59 \cdot 8 \mathrm{ppm}$ indicative of a singular tetrahedrally-coordinated $\mathrm{Al}-\mathrm{O}$ environment.

Figure 8 presents the ${ }^{29} \mathrm{Si},\left\{{ }^{1} \mathrm{H}^{-29} \mathrm{Si}\right\} \mathrm{CP}$ and ${ }^{27} \mathrm{Al}$ MAS NMR spectra of FC3R3. First, the ${ }^{29} \mathrm{Si} \mathrm{MAS} \mathrm{NMR} \mathrm{spectrum} \mathrm{has} \mathrm{a} \mathrm{low}$ signal : noise ratio despite the large number of scans collected. This would suggest a poorly-ordered system that is composed of $\mathrm{Q}^{1}, \mathrm{Q}^{2}, \mathrm{Q}^{3}$ and $\mathrm{Q}^{4}$ siliceous environments. The cross-polarised

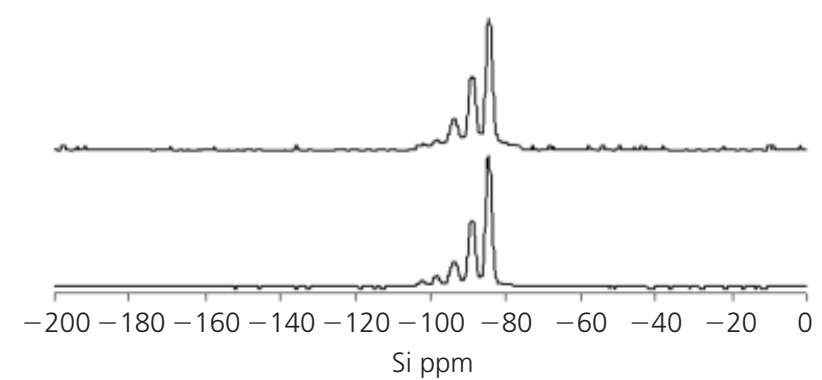

(a)

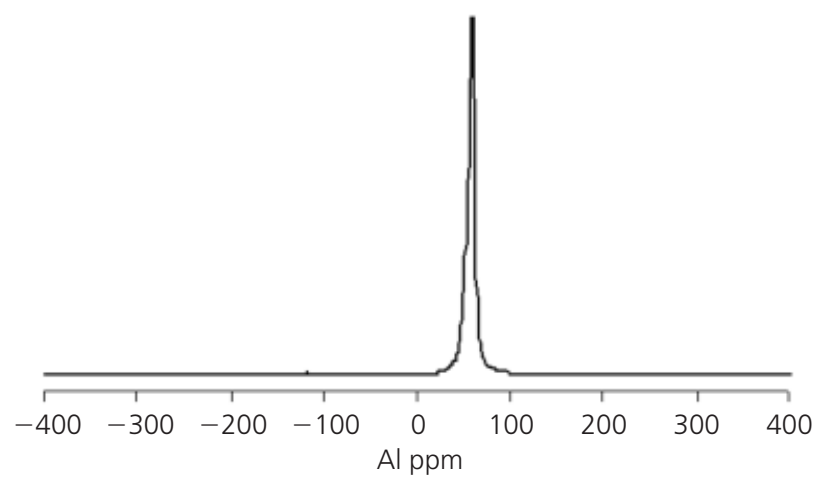

(b)

Figure 7. ${ }^{29} \mathrm{Si}$ MAS ((a), lower), $\left\{{ }^{1} \mathrm{H}-{ }^{29} \mathrm{Si}\right\} \mathrm{CP}\left((\mathrm{a})\right.$, upper) and ${ }^{27} \mathrm{Al}$ MAS NMR (b) spectra of synthetic faujasite 
Pozzolanic activity of a spent fluid catalytic cracking catalyst residue

Garcés, Glasser, Brew, Zornoza and Payá

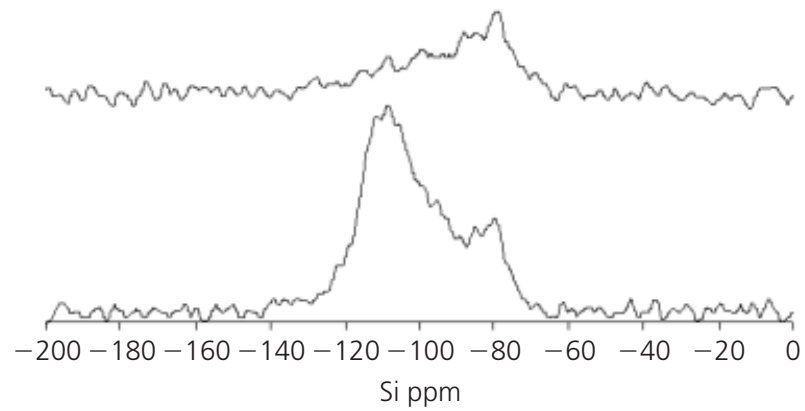

(a)

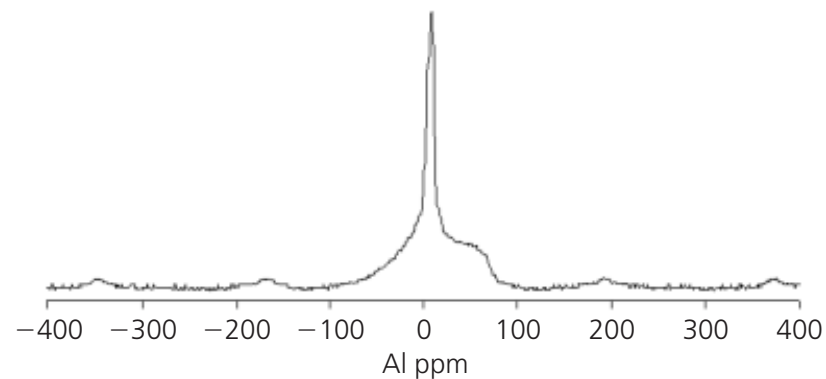

(b)

Figure $8 .{ }^{29} \mathrm{Si}$ MAS ((a), lower), $\left\{{ }^{1} \mathrm{H}^{29} \mathrm{Si}\right\} \mathrm{CP}\left((\mathrm{a})\right.$, upper) and ${ }^{27} \mathrm{Al}$ MAS NMR (b) spectra of FC3R3

spectrum shows that hydroxyls are predominantly associated with the $\mathrm{Q}^{1}$ and $\mathrm{Q}^{2}$ environments - consistent with early formation of $\mathrm{C}-\mathrm{S}-\mathrm{H}$ gel - with minor amounts near the $\mathrm{Q}^{3}$ and $\mathrm{Q}^{4} \mathrm{Si}-\mathrm{O}$ environments. The ${ }^{27} \mathrm{Al}$ MAS spectrum reveals that only some of the aluminium is reactive in spent FC3R residue; that is, all of the pentahedral and some of the tetrahedral aluminium has reacted. The octahedral aluminium appeared unchanged in its chemical shift but still might have been incorporated into the $\mathrm{C}-\mathrm{S}-\mathrm{H}$ gel as reported previously (Sun et al., 2006). The unreactive aluminous fraction was composed of tetrahedral and possibly octahedral aluminium.

Figure 9 presents the ${ }^{29} \mathrm{Si},\left\{{ }^{1} \mathrm{H}_{-}{ }^{29} \mathrm{Si}\right\} \mathrm{CP}$ and ${ }^{27} \mathrm{Al}$ MAS NMR spectra of FC3R28. It can be seen that the ${ }^{29} \mathrm{Si}$ and CP MAS spectra are very different from those of FC3R3, suggesting considerable reaction has taken place. In general, most of the $\mathrm{Q}^{3}$ $\mathrm{Si}-\mathrm{O}$ environments have been consumed to yield relatively sharp $\mathrm{Q}^{1}$ and $\mathrm{Q}^{2} \mathrm{Si}-\mathrm{O}$ environments, inferring improved local order at -79 and $-84 \mathrm{ppm}$, respectively. There is evidence of minor persistent siliceous material in the $\mathrm{Q}^{4}$ spectral region. It is noteworthy that the peak at $-108 \mathrm{ppm}$, present in the FC3R residue starting material, has vanished suggesting its consumption has occurred. From the $\left\{{ }^{1} \mathrm{H}-{ }^{29} \mathrm{Si}\right\} \mathrm{CP}$ MAS NMR spectrum, the hydroxyls are associated with the $\mathrm{Si}-\mathrm{O}$ phases in the $\mathrm{Q}^{1}$ and $\mathrm{Q}^{2}$ regions. The ${ }^{27} \mathrm{Al}$ MAS NMR spectrum shows the $\mathrm{Al}-\mathrm{O}$ environment is predominantly octahedral with minor residual tetrahedral aluminium. This is interpreted as indicating that some aluminium within the FC3R residue is reactive and some is not. Figure 10 presents the ${ }^{29} \mathrm{Si},\left\{{ }^{1} \mathrm{H}-{ }^{29} \mathrm{Si}\right\} \mathrm{CP}$ and ${ }^{27} \mathrm{Al}$ MAS NMR spectra of

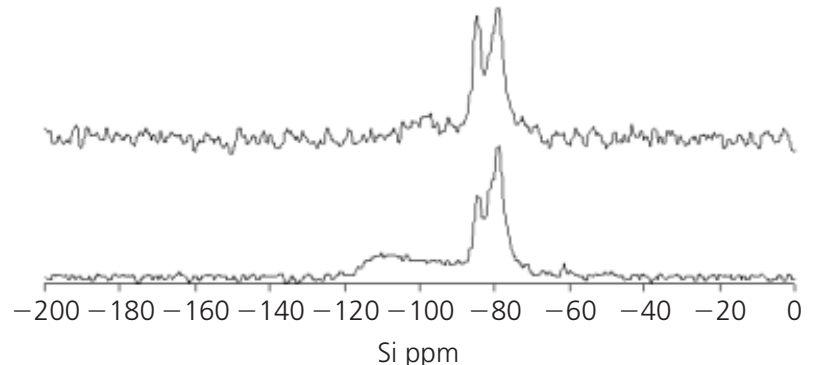

(a)

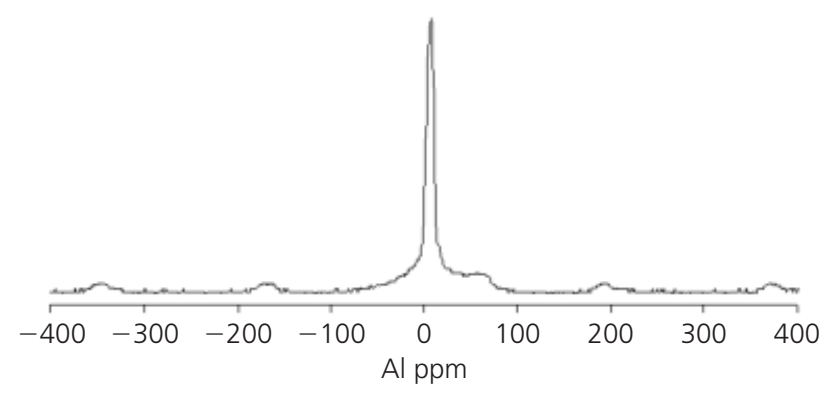

(b)

Figure 9. ${ }^{29} \mathrm{Si}$ MAS ((a), lower), $\left\{{ }^{1} \mathrm{H}^{29}{ }^{29} \mathrm{Si} C \mathrm{CP}\left((\mathrm{a})\right.\right.$, upper) and ${ }^{27} \mathrm{Al}$ MAS NMR (b) spectra of FC3R28

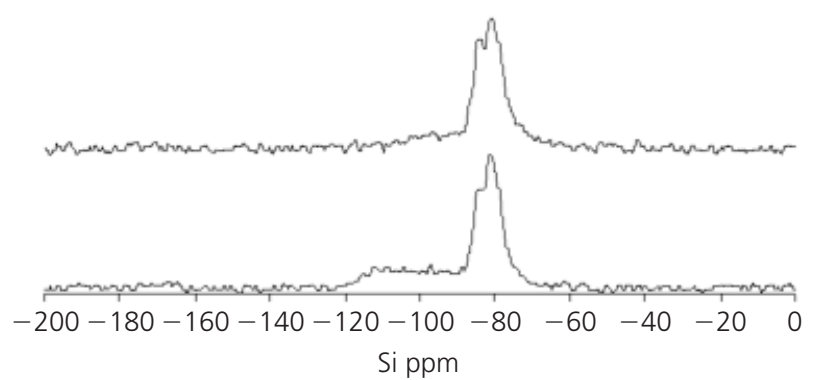

(a)

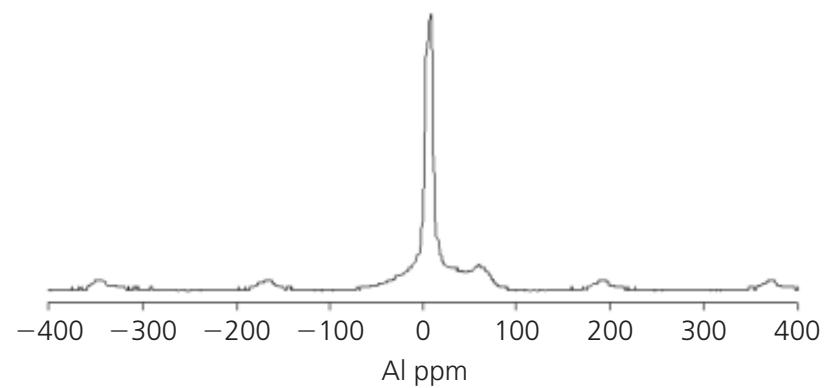

(b)

Figure 10. ${ }^{29} \mathrm{Si} \mathrm{MAS} \mathrm{((a),} \mathrm{lower),}\left\{{ }^{1} \mathrm{H}^{29}{ }^{29} \mathrm{~S}\right\} \mathrm{CP}\left((\mathrm{a})\right.$, upper) and ${ }^{27} \mathrm{Al}$ MAS NMR (b) spectra of FC3R56

FC3R56. The ${ }^{29} \mathrm{Si}$ spectra show that the silicate microstructure has continued to develop - most of the $\mathrm{Q}^{1} \mathrm{Si}-\mathrm{O}$ environments have polymerised to yield two distinct $\mathrm{Q}^{2}$ (located at -81 and $-84 \mathrm{ppm}$ ) environments with minor amounts of siliceous $\mathrm{Q}^{4}$ material persisting. However, the hydroxyls are associated with 
the $\mathrm{Q}^{2}$ silicon nuclei and not with those of $\mathrm{Q}^{4}$. The ${ }^{27} \mathrm{Al}$ MAS NMR spectrum has not changed significantly from 28 to 56 days reaction time, with most aluminium being octahedrally coordinated with minor tetrahedral.

\section{Discussion}

The acceptance of novel pozzolanic materials is a slow process. To speed the acceptance process, spent FC3R catalyst residue was reacted with $\mathrm{Ca}(\mathrm{OH})_{2}$ to quantify its pozzolanic reactivity. XRD and NMR data showed that the as-received residue contained both crystalline and semi-crystalline material. The latter is both siliceous and aluminous and has hydroxyl groups in close proximity. After 3 days, the ${ }^{29} \mathrm{Si}$ and $\left\{{ }^{1} \mathrm{H}^{29} \mathrm{Si}\right\}$ MAS NMR spectra show that the reaction product(s) has a range of $\mathrm{Q}^{2}, \mathrm{Q}^{3}$ and $\mathrm{Q}^{4} \mathrm{Si}-\mathrm{O}(\mathrm{Al})$ environments with resonances between -115 to $-80 \mathrm{ppm}$. Partial pozzolanic reaction is also evidenced by the cross-polarised spectrum: hydroxyls are associated with the $\mathrm{Q}^{2}$ silicon environments, indicative of $\mathrm{C}-\mathrm{S}-\mathrm{H}$ gel, albeit siliconpoor. However, the large, broad $\mathrm{Q}^{3}$ peaks in both the ${ }^{29} \mathrm{Si}$ and $\left\{{ }^{1} \mathrm{H}-{ }^{29} \mathrm{Si}\right\}$ CP spectra suggested that significant FC3R residue remained unreacted after only 3 days. With respect to aluminium, all of the pentahedral and the majority of tetrahedral fractions were consumed within the first 3 days of reaction, leaving a residue material containing octahedral and a minor quantity of tetrahedral aluminium. The remaining octahedrally-coordinated aluminium appeared to be part of a crystalline phase due to its sharpness - possibly stratlingite-like, as suggested by XRD, although stratlingite contains both tetrahedral and octahedral aluminium.

The pozzolanic reaction continued with time. After 28 days, diminution of reflection and vibration intensities were observed in the XRD patterns and FT-IR spectra presented in Figures 3 and 5 , respectively. The diminution was due to reaction between FC3R and $\mathrm{Ca}(\mathrm{OH})_{2}$ and the NMR evidence shows that during this reaction, much of the $\mathrm{Q}^{3} \mathrm{Si}-\mathrm{O}$ environments were consumed to yield $\mathrm{Q}^{1}$ and $\mathrm{Q}^{2} \mathrm{Si}-\mathrm{O}$ environments. These were typically observed in the $\mathrm{Q}^{1}$ and $\mathrm{Q}^{2}$ region of the spectrum and assigned to $\mathrm{C}-\mathrm{S}-\mathrm{H}$ gel. From the $\left\{{ }^{1} \mathrm{H}-{ }^{29} \mathrm{Si}\right\} \mathrm{CP}$ MAS NMR spectrum in Figure 9, hydroxyls were associated with the $\mathrm{Si}-\mathrm{O}$ phases in the $\mathrm{Q}^{1}$ or $\mathrm{Q}^{2}(\mathrm{Al})$ region, in accordance with other evidence corroborating the formation of a $\mathrm{C}-\mathrm{S}-\mathrm{H}$ gel or $\mathrm{C}-\mathrm{A}-\mathrm{S}-\mathrm{H}$ gel, or both. Poorly-ordered $\mathrm{Q}^{4}$ siliceous material still persisted and ${ }^{27} \mathrm{Al}$ MAS NMR evidence showed that not all of the tetrahedral aluminium had reacted within 28 days. After 56 days, the two separate $\mathrm{Q}^{1}$ and $\mathrm{Q}^{2}$ silicon regions continued to develop into characteristic $\mathrm{C}-\mathrm{S}-\mathrm{H}$ gel resonances. The persistence of $\mathrm{Q}^{4}$ siliceous and tetrahedral aluminous material infers that not all the spent residue is reactive and that some of the silicon and aluminium will not contribute to formation of cementitious bonds within 56 days.

Therefore, spent catalysts seem to offer a potential use as pozzolanic material to be incorporated in mortars and concrete. In fact, other authors have reported good mechanical and durability properties when they have been used as cement replacement. This residue has been mechanically tested to show a proper compatibility with several types of cements (Zornoza et al., 2007). With regard to durability aspects, the protection that blended cements incorporating FC3R offer to steel reinforcements is similar or better than plain Portland cement mortars when a carbonation or chloride-induced attack is considered (Zornoza et al., 2008, 2009). The resistance to sulfates of mortars has also been improved by the incorporation of spent catalyst in mix formulations by reducing the strength decrease that experimented plain cement mortars (Bukowska et al., 2003). However, one factor that should be considered is the maximum quantity of this pozzolan that can be used to obtain an optimal performance, which most authors limit to 15 to $20 \%$ of cement weight.

\section{Conclusion}

The following conclusions can be drawn from the results from the present study.

(a) XRD, FT-IR and NMR data demonstrate the pozzolanic activity of $\mathrm{FC} 3 \mathrm{R}$ when mixed with $\mathrm{Ca}(\mathrm{OH})_{2}$ pastes.

(b) According to ${ }^{29} \mathrm{Si}$ and ${ }^{27} \mathrm{Al}$ MAS NMR data, the pozzolanic reaction of spent catalyst yields mainly linear chains of silicates with possible incorporation of predominantly octahedral aluminium. On the basis of the results obtained, solid-state NMR was the most suitable technique to monitor the development of the pozzolanic reaction.

(c) A fraction of FC3R - composed of $\mathrm{Q}^{4}$ siliceous material and tetrahedral aluminium - did not react and persisted even after 56 days hydration.

(d) Spent faujasite catalyst shows promise as a potential pozzolanic material. Products of reaction with $\mathrm{Ca}(\mathrm{OH})_{2}$ include $\mathrm{C}-\mathrm{A}-\mathrm{S}-\mathrm{H}$ and an $\mathrm{AFm}$ phase, probably stratlingite-like.

\section{REFERENCES}

Bukowska M, Pacewska B and Wilinska I (2003) Corrosion resistance of cement mortars containing spent catalyst of fluidized bed cracking (FBCC) as an additive. Journal of Thermal Analysis and Calorimetry 74(3): 931-942.

Chen H-L, Tseng Y-S and Hsu K-C (2004) Spent FCC catalyst as a pozzolanic material for high-performance mortars. Cement and Concrete Composites 26(6): 657-664.

Hsu K-C, Tseng Y-S, Ku F-F and Su N (2001) Oil cracking waste catalyst as an active pozzolanic material for superplasticized mortars. Cement and Concrete Research 31(12): 1815-1820.

Pacewska B, Wilinska I and Bukowska M (2000) Hydration of cement slurry in the presence of spent cracking catalyst. Journal of Thermal Analysis and Calorimetry 60(1): 71-78.

Pacewska B, Bukowska M, Wilinska, I and Swat M (2002) Modification of the properties of concrete by a new pozzolan. A waste catalyst from the catalytic process in a fluidized bed. Cement and Concrete Research 32(1): 145-152.

Payá J, Monzó J and Borrachero MV (1999) Fluid catalytic cracking catalyst residue (FCC). An excellent mineral byproduct for improving early-strength development of cement 
mixtures. Cement and Concrete Research 29(11): $1773-$ 1779.

Payá J, Monzó J and Borrachero MV (2001) Physical, chemical and mechanical properties of fluid catalytic cracking catalyst residue (FCC) blended cements. Cement and Concrete Research 31(1): 57-61.

Payá J, Monzó J, Borrachero MV, et al. (2002) Advantages in the use of fly ashes in cements containing pozzolanic combustion residues: silica fume, sewage sludge ash, spent fluidized bed catalyst and rice husk ash. Journal of Chemical Technology and Biotechnology 77(3): 331-335.

Payá J, Monzó J, Borrachero MV and Velázquez S (2003a) Evaluation of the pozzolanic activity of fluid catalytic cracking residue (FCC). Thermogravimetric analysis studies on FCC-Portland cement pastes. Cement and Concrete Research 33(4): 603-609.

Payá J, Monzó J, Borrachero MV, Velázquez S and Bonilla M (2003b) Determination of the pozzolanic activity of fluid catalytic cracking residue. Thermogravimetric analysis studies on FC3R-lime pastes. Cement and Concrete Research 33(7): 1085-1091.

Payá J, Borrachero MV, Monzo J and Soriano L (2009) Studies on the behaviour of different spent fluidized-bed catalytic cracking catalysts on Portland cement. Materiales de Construccion 59(296): 39-54.

Su N, Fang H-Y, Chen Z-H and Lu F-S (2000) Reuse of waste catalysts from petrochemical industries for cement substitution. Cement and Concrete Research 30(11): 11, $1773-1783$.

Su N, Chen Z-H and Fang H-Y (2001) Reuse of spent catalyst as fine aggregate in cement mortar. Cement and Concrete Composites 23(1): 111-118.

Sun GK, Young F and Kirkpatrick RJ (2006) The role of Al in C-S-H: NMR, XRD and compositional results for precipitated samples. Cement and Concrete Research 36(1): $18-29$.

Wu J-H, Wu W-L and Hsu K-C (2003) The effect of waste oilcracking catalyst on the compressive strength of cement pastes and mortars. Cement and Concrete Research 33(2): 245-253.

Zornoza E, Garcés P, Monzó J, Borrachero MV and Payá J (2007) Compatibility of fluid catalytic cracking catalyst residue (FC3R) with various types of cement. Advances in Cement Research 19(3): 117-124.

Zornoza E, Garcés P and Payá J (2008) Corrosion rate of steel embedded in blended Portland and fluid catalytic cracking catalyst residue (FC3R) cement mortars. Materiales de Construcción 58(292): 27-43.

Zornoza E, Garcés P, Payá J and Climent MA (2009) Improvement of the chloride ingress resistance of OPC mortars by using spent cracking catalyst. Cement and Concrete Research 39(2): 126-139.

\section{WHAT DO YOU THINK?}

To discuss this paper, please submit up to 500 words to the editor at www.editorialmanager.com/acr by 1 October 2011. Your contribution will be forwarded to the author(s) for a reply and, if considered appropriate by the editorial panel, will be published as a discussion in a future issue of the journal. 